\title{
Pharmacologically induced alcohol craving in treatment seeking alcoholics correlates with alcoholism severity, but is insensitive to acamprosate
}

\author{
John C Umhau', Melanie L Schwandt', Julie Usala', Christopher Geyer', Erick Singley', David T George' and \\ Markus Heilig*, \\ 'Laboratory of Clinical and Translational Studies, National Institute on Alcohol Abuse and Alcoholism, Bethesda, MD, USA
}

\begin{abstract}
Modulation of alcohol craving induced by challenge stimuli may predict the efficacy of new pharmacotherapies for alcoholism. We evaluated two pharmacological challenges, the $\alpha_{2}$-adrenergic antagonist yohimbine, which reinstates alcohol seeking in rats, and the serotonergic compound meta-chlorophenylpiperazine (mCPP), previously reported to increase alcohol craving in alcoholics. To assess the predictive validity of this approach, the approved alcoholism medication acamprosate was evaluated for its ability to modulate challenge-induced cravings. A total of 35 treatment seeking alcohol dependent inpatients in early abstinence were randomized to placebo or acamprosate (2997 mg daily). Following two weeks of medication, subjects underwent three challenge sessions with yohimbine, mCPP or saline infusion under double blind conditions, carried out in counterbalanced order, and separated by at least 5 days. Ratings of cravings and anxiety, as well as biochemical measures were obtained. In all, 25 subjects completed all three sessions and were included in the analysis. Cravings were modestly, but significantly higher following both yohimbine and mCPP challenge compared with saline infusion. The mCPP, but not yohimbine significantly increased anxiety ratings. Both challenges produced robust ACTH, cortisol and prolactin responses. There was a significant correlation between craving and the degree of alcoholism severity. Acamprosate administration did not influence craving. Both yohimbine and mCPP challenges lead to elevated alcohol craving in a clinical population of alcoholics, and these cravings correlate with alcoholism severity. Under the experimental conditions used, alcohol cravings induced by these two stimuli are not sensitive to acamprosate at clinically used doses.
\end{abstract}

Neuropsychopharmacology (20II) 36, II78-I I86; doi:I0.1038/npp.2010.253; published online 2 February 201 I

Keywords: alcoholism; craving; yohimbine; meta-chlorophenylpiperazine; acamprosate

\section{INTRODUCTION}

Alcohol dependence is characterized by cycles of excessive alcohol consumption, interspersed with intervals of abstinence. Relapse, ie return to uncontrolled alcohol use following abstinence, is a key element of the disease, and therefore an important target for novel treatments (McLellan et al, 2000). Preclinical studies have identified a growing number of candidate medications with an ability to block reinstatement of alcohol seeking in experimental animals, a model of human relapse (Heilig and Egli, 2006; Heilig and Koob, 2007). These results offer the promise of novel

*Correspondence: Dr M Heilig, Laboratory of Clinical and Translational Studies, NIAAA/NIH, 10 Center Dr, Bethesda, MD 20892-I I08, USA, Tel: + | 30 | 435 9386, Fax: + | 301402044 ,

E-mail: markus.heilig@mail.nih.gov

Received II October 20 I0; revised 30 November 2010; accepted 17 December 2010 treatments, but translation into human therapies remains to be carried out.

Human surrogate marker strategies might facilitate translation and clinical development of new pharmacotherapies for alcoholism. In this type of approach, closely controlled human laboratory studies are carried out in limited numbers of subjects, and are used to examine shortterm effects of experimental therapeutics that might be predictive of clinical efficacy. The appeal of this strategy is its potential for providing evidence of target engagement and proof-of-principle. This information can guide selection of candidate medications that merit being advanced to full scale clinical trials, and can also inform the selection of optimal target populations for these trials (Sinha, 2009).

Although the construct of craving continues to be debated (Tiffany and Wray, 2009; Kranzler et al, 1999; Tiffany, 1990), craving assessed under laboratory conditions can predict subsequent clinical course (Fox et al, 2007; Sinha et al, 2006), and effects of alcoholism medications on craving have been reported to correlate with drinking 
outcomes (Anton et al, 1996; O'Malley et al, 2002; Flannery et al, 2003). Psychometrically sound measures of cravings have been developed, either by focusing on the here-andnow situation (Bohn et al, 1995), integrating the amount of alcohol-related cognitions and behaviors over a preceding interval (Anton et al, 1996), or using items that combine these approaches (Flannery et al, 1999). Therefore, craving measures may offer surrogate outcomes predictive of clinical efficacy. Endocrine responses frequently accompany subjective craving responses, and may offer additional potentially useful surrogate measures (Hillemacher et al, 2006; Ooteman et al, 2007). For instance, prolactin elevations have been positively correlated with alcohol craving (Hillemacher et al, 2006), while an inverse correlation with craving was found for cortisol (O'Malley et al, 2002).

Psychological stressors and alcohol-associated cues have long been recognized as potent relapse triggers in human addicts, and trigger relapse-like behavior in animal models (Brownell et al, 1986; Epstein et al, 2006). Accordingly, these types of stimuli have been used to induce cravings under experimental conditions (Monti et al, 1993; Sinha, 2009), and have successfully been used to evaluate experimental therapeutics in our laboratory (George et al, 2008). Responses to these stimuli are, however, somewhat variable. For instance, $\sim 20-30 \%$ of alcohol dependent individuals do not report cravings in response to alcohol-associated cues. This degree of variability decreases power, and makes craving responses induced by psychological stimuli technically challenging to use as surrogate markers. Pharmacological challenges might be hypothesized to produce more robust and reproducible responses, better suited for medication development. Two candidates for pharmacological challenges are suggested by animal and human studies: the $\alpha_{2}$ adrenergic antagonist yohimbine, which reinstates alcohol seeking in rats in a manner similar to stress (Le et al, 2005), but was not effective in inducing cravings in human alcohol dependent subjects in the one published previous attempt (Krystal et al, 1994); and meta-chlorophenylpiperazine (mCPP), which did produce a craving response (Krystal et al, 1994; George et al, 1997).

If the preclinical findings with yohimbine can be translated to craving responses in human alcoholics, this approach might be particularly useful in attempts to develop medications that target stress-related mechanisms. Similar to stress, administration of yohimbine to rats triggers relapse-like behavior (Le et al, 2005), and activates neurocircuitry similar to that activated by environmental stressors capable of reinstating alcohol seeking (Funk et al, 2006). Stress-induced reinstatement of alcohol seeking is largely driven by central Corticotropin-Releasing Hormone 1 (CRH1) receptors, and is enhanced in animals with a prolonged history of dependence (Le et al, 2000; Liu and Weiss, 2002; Gehlert et al, 2007). Accordingly, yohimbineinduced reinstatement of alcohol seeking is CRH1-dependent (Marinelli et al, 2007). Antagonism of central CRH1 receptors has emerged as a high priority candidate awaiting human translation (Heilig and Koob, 2007). On the basis of the observations reviewed above, modulation of yohimbineinduced alcohol craving might offer a theoretically attractive approach for initial human evaluation of CRH1 antagonists. However, the predictive validity of this approach remains untested.

Alcohol seeking and relapse can be conceptualized as being driven by positive reinforcement, and the related phenomenon of 'reward craving', or by negative reinforcement, related to 'relief craving' (Heinz et al, 2003). Although neither of the two approved alcoholism medications with central actions, naltrexone and acamprosate, directly targets stress-induced craving, the latter has been postulated to target 'relief craving' (Littleton and Zieglgansberger, 2003), and could potentially help establish the predictive validity of a model based on yohimbine-induced responses. An ability of acamprosate to suppress craving has been found in some clinical trials (Chick et al, 2000; Pelc et al, 1997), but not in others (Tempesta et al, 2000; Besson et al, 1998; Paille et al, 1995; Morley et al, 2006). Laboratory based studies test craving responses under highly standardized conditions, and may allow better detection of effects with modest size (Sinha, 2009). Accordingly, under laboratory conditions, acamprosate was recently reported to suppress craving responses in patients with alcohol dependence (Hammarberg et al, 2009).

Here, we therefore carried out a laboratory study in a clinical population of treatment-seeking alcoholics in early abstinence, with the objective to address two questions. First, we examined whether a yohimbine challenge would be able to induce a craving response, as measured using an established and psychometrically validated craving scale, the Penn Alcohol Craving Scale (PACS). mCPP was used as a positive control, because of its previously described ability to induce alcohol cravings in humans (Krystal et al, 1994; George et al, 1997). Second, in an attempt to evaluate the predictive validity of this model, craving responses to the two stimuli were evaluated in subjects randomized to pre-treatment with acamprosate or placebo.

\section{MATERIALS AND METHODS}

\section{Participants}

The flow of participants is shown in Figure 1, and descriptive participant characteristics are given in Table 1. All participants underwent a telephone prescreening to select treatment-seeking alcohol dependent individuals between the ages of 21 and 65, who had used alcohol in the past month. Individuals were excluded if they were pregnant or had significant complicating medical conditions such as infection with human immunodeficiency virus; or if they had a lifetime diagnosis of a significant psychiatric illness, such as dementia, a non-substance induced psychotic disorder, or bipolar illness. Because of the anxiety-provoking nature of the challenge stimuli used in the study, patients with a diagnosis of panic disorder were also excluded. They were also excluded if they had received any psychiatric medications in the two weeks preceding the study, or fluoxetine in the last five preceding weeks. Complete eligibility criteria are available at http:// www.clinicaltrials.gov; trial identifier NCT00605904.

\section{Inpatient Treatment Program}

Alcohol dependent individuals who successfully completed the telephone screening were offered admission to a 32-day 


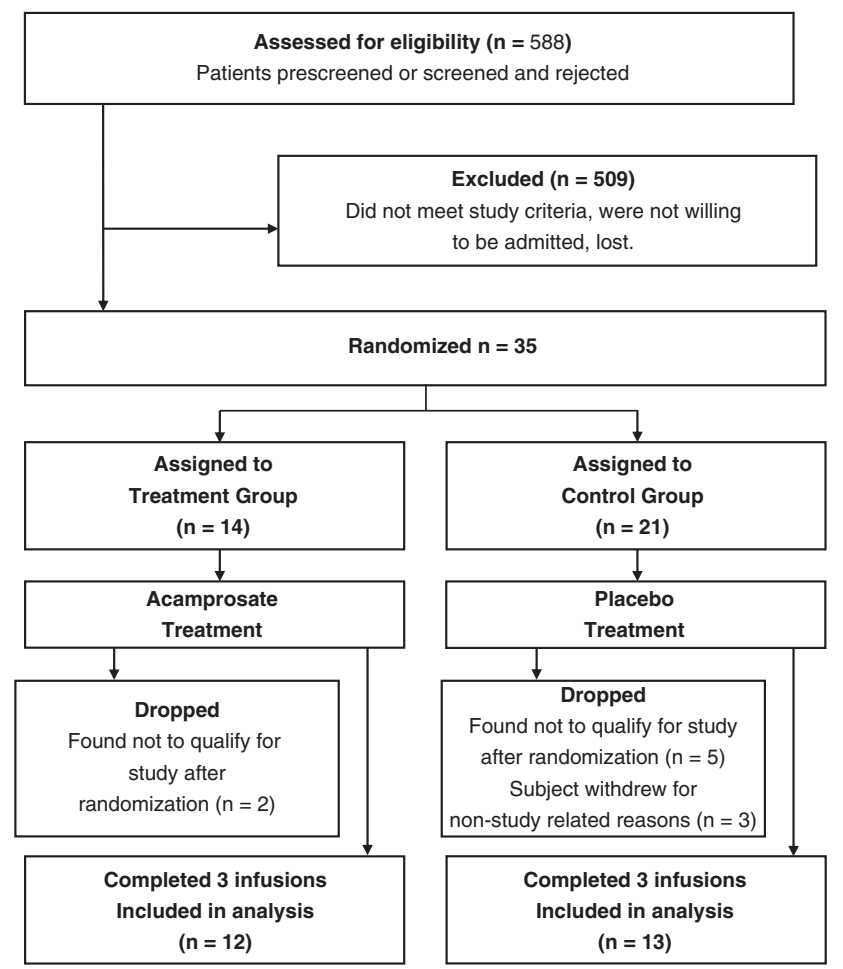

Figure I CONSORT graph showing the flow of the study participants.

inpatient protocol at the NIH Clinical Research Center. At the time of admission, measurements were made of the breath alcohol concentration and the percentage of carbohydrate deficient transferin (CDT\%) to give an objective measurement of recent alcohol consumption. Withdrawal symptoms were assessed using the revised Clinical Institute Withdrawal Assessment for Alcohol scale (CIWA-Ar; (Sullivan et al, 1989)). Throughout the study, subjects participated in a standard behavioral inpatient alcohol rehabilitation program, but did not receive any prescription medications other than diazepam as needed for treatment of withdrawal during the first 5 days of hospitalization. Vitamin $B_{1}$ (thiamine) supplementation was provided according to clinical guidelines. Smoking and use of other tobacco products was not restricted except on challenge days, as described below.

After completion of withdrawal treatment if any, informed consent was obtained in accordance with the Declaration of Helsinki and the NIH Institutional Review Board. During each inpatient week of alcohol rehabilitation, a standard clinical blood chemistry panel was obtained. To quantify spontaneous alcohol craving, the Penn Alcohol Craving Scale (PACS) was administered each week (Flannery et al, 1999). To quantify the participants' anxiety, the State-Trait Anxiety Inventory (STAI Form Y-2) was administered at the beginning and the end of the inpatient stay (Spielberger et al, 1970). Patients were assessed for a diagnosis of alcohol dependence, and any comorbid psychiatric disorders using the Structured Clinical Interview for DSM-IV Axis I Disorders Diagnosis (SCID IV; (First et al, 1997)). Severity of alcohol dependence was assessed using the Alcohol Dependence Scale (ADS; (Skinner and Horn, 1984)) and the Addiction Severity Index (ASI), which
Table I Subject Characteristics and Baseline Descriptive Variables

\begin{tabular}{|c|c|c|}
\hline Variable & Acamprosate & Placebo \\
\hline N & 12 & 13 \\
\hline \multirow[t]{2}{*}{ Gender } & I I Males & I I Males \\
\hline & I Female & 2 Females \\
\hline \multirow[t]{3}{*}{ Race } & 8 White & 6 White \\
\hline & 3 Black & 7 Black \\
\hline & I Asian & \\
\hline Age (years) & $44.4 \pm 1.6$ & $44.1 \pm 1.9$ \\
\hline Weight (kg) & $84.8 \pm 3.9$ & $76.3 \pm 4.4$ \\
\hline Body mass index & $28.2 \pm 1.4$ & $24.9 \pm 1.3$ \\
\hline Smokes cigarettes $(\mathrm{N})$ & 12 & 9 \\
\hline Fagerstöm nicotine dependence score & $5.0 \pm 0.6$ & $2.6 \pm 0.7$ \\
\hline \multicolumn{3}{|l|}{ Addiction severity index (ASI) } \\
\hline Medical composite score & $0.12 \pm 0.09$ & $0.12 \pm 0.08$ \\
\hline Employment composite score ${ }^{a}$ & $0.69 \pm 0.09$ & $0.41 \pm 0.08$ \\
\hline Alcohol composite score & $0.81 \pm 0.03$ & $0.75 \pm 0.05$ \\
\hline Drug composite score & $0.05 \pm 0.02$ & $0.02 \pm 0.02$ \\
\hline Legal composite score & $0.17 \pm 0.06$ & $0.06 \pm 0.03$ \\
\hline Family composite score & $0.19 \pm 0.06$ & $0.21 \pm 0.08$ \\
\hline Psychiatric composite score & $0.11 \pm 0.04$ & $0.06 \pm 0.03$ \\
\hline
\end{tabular}

Penn alcohol craving scale (PACS)

Day 4 baseline

$5.83 \pm 1.33 \quad 6.00 \pm 1.28$

Alcohol dependence score (ADS)

$18.8 \pm 2.9 \quad 18.8 \pm 1.8$

Timeline followback (TLFB - 30 days before admission

Total drinks

Drinking days

Heavy drinking days

Average number of drinks per day

$393.3 \pm 45.9 \quad 336.3 \pm 50.6$

$24.2 \pm 1.7 \quad 22.7 \pm 2.6$

$23.5 \pm 1.8 \quad 21.3 \pm 2.7$

$13.1 \pm 1.5 \quad 11.2 \pm 1.7$

Breath alcohol level at admission

$0.07 \pm 0.04 \quad 0.10 \pm 0.04$

Clinical institute withdrawal assessment

of alcohol scale (CIWA-Ar)

Maximum score

$5.0 \pm 1.7 \quad 5.8 \pm 1.4$

State-trait anxiety inventory (STAl)

Trait anxiety score

$36.5 \pm 2.2 \quad 38.3 \pm 3.1$

Laboratory assessments at admission

$\gamma$ Glutamyltransferase (GGT)

$233.9 \pm 76.0 \quad 213.4 \pm 74.1$

Albumin

$3.9 \pm 0.1 \quad 4.1 \pm 0.1$

Alkaline phosphatase

$84.3 \pm 7.8 \quad 79.8 \pm 5.7$

ALT/GPT (alanine transaminase)

$68.2 \pm 12.2 \quad 72.9 \pm 13.6$

AST/GOT (aspartate transaminase)

$69.7 \pm 18.2 \quad 82.9 \pm 20.4$

CDT\% (carbohydrate-deficient transferrin)

$0.10 \pm 0.03 \quad 0.14 \pm 0.04$

aEmployment score was significantly higher in the acamprosate group $(F(I, 2 I)=$ $5.87, p=0.02)$; none of the other characteristics differed between groups. 
quantifies problem severity in seven domains (McLellan et al, 1992). Alcohol consumption during the preceding 3 months was quantified using time-line follow-back (TLFB; (Sobell and Sobell, 1992)).

Pharmacological intervention. After completion of any alcohol withdrawal treatment if needed, participants were randomized to receive $999 \mathrm{mg}$ of acamprosate every $8 \mathrm{~h}$ or matching placebo. Randomization was conducted by the $\mathrm{NIH}$ Clinical Center pharmacy, and investigators and clinical staff were blind to the randomization process. A double blind was achieved by encapsulating commercially obtained acamprosate and manufacturing matching placebo.

Yohimbine, $m C P P$, or placebo challenge. Each participant completed yohimbine and mCPP challenge sessions as well as a saline control session, in a counterbalanced order under double-blind conditions. The test sessions were separated by 5-7 days. Participants fasted and abstained from tobacco products $9 \mathrm{~h}$ before the test sessions to replicate conditions used in previous studies (Krystal et al, 1994; George et al, 1997). At 0900 hours on each test day, $\sim 1 \mathrm{~h}$ after insertion of an intravenous line, participants received two 10-min infusions designed to provide appropriate blinding of $\mathrm{MCPP}$ and yohimbine administration while replicating previous studies (Charney et al, 1987; Southwick et al, 1997; Krystal et al, 1994; Stine et al, 2002). On the saline control day, both infusions consisted of $0.9 \%$ saline solution. On the mCPP test day, both infusions contained $0.05 \mathrm{mg} / \mathrm{kg}$ of $\mathrm{mCPP}$ for a total of $0.1 \mathrm{mg} / \mathrm{kg}$ over $20 \mathrm{~min}$. On the yohimbine test day, participants received an infusion of yohimbine $(0.4 \mathrm{mg} / \mathrm{kg}$ administered over $10 \mathrm{~min}$ ) and a $10-\mathrm{min}$ infusion of saline solution.

Subjective, physiological, and biochemical measures. On the basis of pilot data, the primary outcome measure of the study was the craving in response to the infusions, as measured by the Penn Alcohol Craving Scale (PACS). The PACS is a 5-item self-administered instrument that measures frequency, intensity, and duration of thoughts about drinking, the ability to resist drinking, and a selfrating of craving (Flannery et al, 1999). Repeated ratings using the Alcohol Urges Questionnaire (AUQ) were also obtained for comparison with previous results. Both instruments have been shown to be psychometrically sound assessments of craving (Bohn et al, 1995; Flannery et al, 1999). Among available rating scales, our pilot data indicated that the AUQ is most sensitive to rapid change, but shows a high degree of variability. The PACS also shows sensitivity to within-day change, while the variability of this scale appears lower. The PACS was completed 15 min before and $180 \mathrm{~min}$ after the start of the infusions. For the $180 \mathrm{~min}$ time point, participants were instructed to answer all five scale items based on how they felt since the start of the infusion. The AUQ was completed $15 \mathrm{~min}$ before the start of the infusions and at 15, 30, 40, 60, 120, and 180 min after the start of the infusions. Secondary outcome measures also included anxiety, as measured by the State-Trait Anxiety Inventory (STAI Form Y-1), and plasma levels of prolactin, adrenocorticotropic hormone (ACTH), and cortisol. The
STAI was completed at the same time points as the AUQ. Blood samples for prolactin, ACTH, and cortisol were obtained $15 \mathrm{~min}$ before the start of the infusion, and at 0,30 , $40,60,120$, and $180 \mathrm{~min}$ after the start of the infusions. Blood pressure and pulse were also monitored throughout the procedure.

\section{Statistical Procedures}

Data were examined for homogeneity of variance and distribution, and analyzed using general linear models (GLM, Statistica 6.0, StatSoft, Tulsa, OK). One way analysis of variance (ANOVA) was used to compare baseline characteristics between the randomized treatment groups, while repeated measures ANOVA was used to analyze primary and secondary outcomes associated with yohimbine and mCPP challenge. The latter analyses included pharmacological treatment (acamprosate $v s$ placebo) as the between subjects factor and both challenge treatment (yohimbine, mCPP, saline) and time point (number varied according to outcome) as the within subjects factors. According to a pre-defined data-analysis plan, all potentially contributing covariates (order of the challenge presentation, baseline characteristics, Table 1) were evaluated by initial inclusion in the model, and were retained if they contributed significantly or reduced the residual variance, measured as sum of squares attributable to the error term, by at least 10\%; otherwise they were dropped from the model. Sex was not included as a factor in analyses because of the small number of female participants. Potential relationships between neuroendocrine measures (prolactin, ACTH, and cortisol) and subjective craving during each of the challenges were evaluated using correlation analyses, with area under the curve calculations used to represent the neuroendocrine measures. The significance level was set at a probability of 0.05 .

\section{RESULTS}

\section{Participant Characteristics}

The randomization generated groups did not differ on baseline variables, with the exception of a higher employment score on the ASI among participants assigned to acamprosate treatment (Table 1).

\section{Adverse Events}

There were no significant adverse effects associated with acamprosate treatment. One participant had an elevation in blood pressure during the yohimbine infusion.

\section{Alcohol Craving}

No main or interactive effects of order of challenge presentation were found for either of the craving outcome measures (all $p>0.05$ ). Analysis of PACS scores following challenge treatments showed a main effect of challenge on alcohol craving at $180 \mathrm{~min}$ after infusion $(\mathrm{F}(2,40)=8.03$, $p=0.001)$. In this analysis, ADS score was a significant covariate, and was retained in the final model $(\mathrm{F}(1,20)=$ 9.43, $p=0.006)$. On post hoc analysis, both $\mathrm{mCPP}$ and 
yohimbine resulted in significantly increased craving scores compared with the saline control session (Newman-Keuls post hoc tests, both $p<0.05$; Figure 2 ). There was no significant effect of acamprosate treatment on PACS scores during the challenge treatments $(\mathrm{F}(1,20)=0.27, p=0.61)$.

Similar, although somewhat less robust results were obtained when craving was measured using the AUQ. There was a significant main effect of challenge on AUQ scores in response to the infusions $(\mathrm{F}(2,32)=4.21, p=0.02)$. Significant covariates that were retained in the model were once again ADS score $(\mathrm{F}(1,16)=8.58, p=0.01)$ and baseline AUQ score from Day 4 of inpatient treatment $(\mathrm{F}(1,16)=12.78, p=0.003)$. Post hoc tests for differences

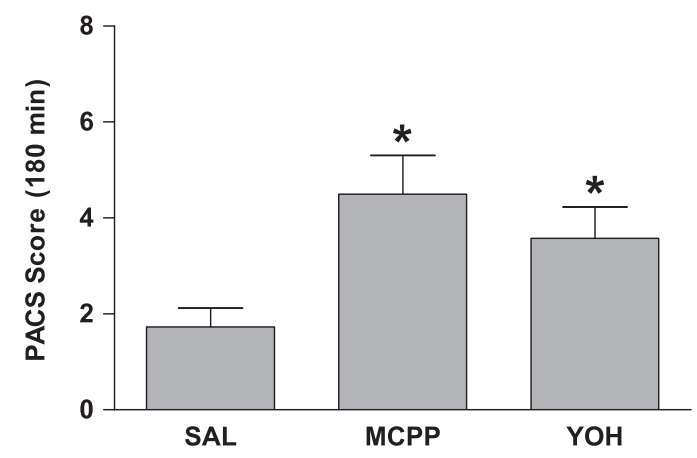

Figure 2 Effects of yohimbine and $\mathrm{mCPP}$ challenge on alcohol craving as measured by the PACS. At 180 min after infusion, craving measures were significantly higher in response to $\mathrm{mCPP}$ and yohimbine challenge compared with saline. Main challenge effect: $p<0.000 \mathrm{I}$; $*_{p}<0.05$ compared with saline on Newman-Keuls post hoc tests. Data are means \pm SEM For detailed statistics, see Results. between $\mathrm{mCPP}$ and saline control as well as yohimbine and saline control were both only at trend level (Newman-Keuls posthoc tests, both $p=0.07$ ), but in both cases the trend was for an elevation, consistent with the PACS results. A similar result was obtained when analyzing peak AUQ scores, although this analysis appeared less sensitive (main effect of challenge: $(\mathrm{F}(2,46)=3.54, p=0.04)$; no significant main or interactive effects of treatment; post hoc tests (NewmanKeuls, $p<0.05)$ showing that the yohimbine challenge induced peak AUQ scores higher than those in response to saline infusion, but no significant difference between the mCPP and saline conditions). No covariates met criteria for being retained in this model.

Further exploration of the relationship between alcohol dependence severity and alcohol craving as measured by the PACS was conducted using regression analyses. Multiple regression using PACS score at $180 \mathrm{~min}$ as the dependent variable, and ADS score and PACS score obtained $15 \mathrm{~min}$ before the infusion as the predictor variables, revealed a positive correlation between ADS score and craving both under the mCPP $\left(\mathrm{R}^{2}=0.49, p<0.001\right.$; Figure $\left.3 \mathrm{a}\right)$ and the yohimbine challenge $\left(\mathrm{R}^{2}=0.40, p=0.003\right.$; Figure $\left.3 \mathrm{~b}\right)$, but not under the saline condition (Figure $3 \mathrm{c}$ ).

\section{Anxiety}

The analysis of STAI-Y1 scores during the challenge treatments showed a main effect of time point $(F(6,108)=$ $5.60, p=0.00005)$ and an interaction of challenge and time point $(F(12,216)=2.57, p=0.003)$. Severity of nicotine dependence score was a significant covariate in the final model $(\mathrm{F}(1,18)=17.05, p=0.0006)$. The $\mathrm{mCPP}$ challenge resulted in significantly higher STAI-Y1 Scores at the 30, 40,
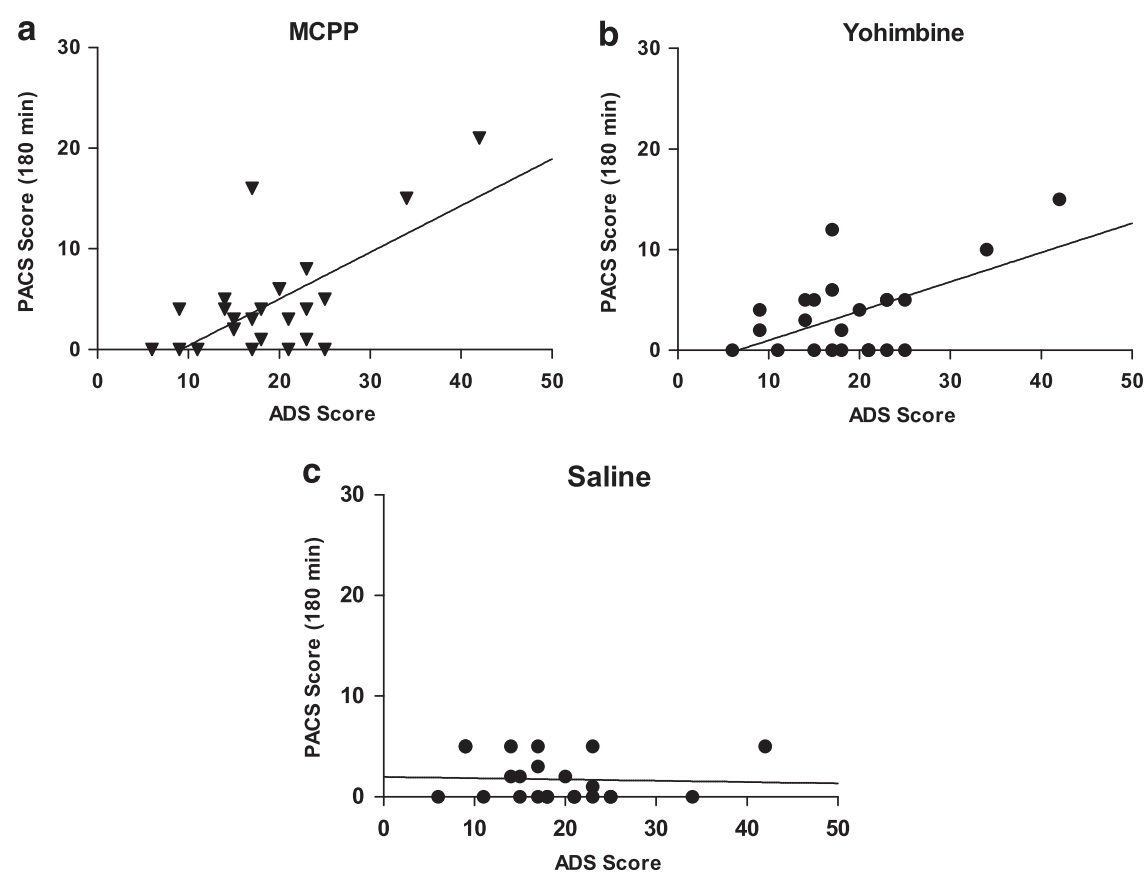

Figure 3 Correlation between alcohol dependence severity and alcohol craving under (a) mCPP and (b) yohimbine challenge, as well as under (c) saline. Plots represent simple linear regression. For both mCPP and yohimbine, multiple regression analyses were performed with ADS score and PACS scores obtained at $15 \mathrm{~min}$ before the infusion as the predictor variables. All regression analyses for the saline condition indicated no relationship between ADS score and craving. 


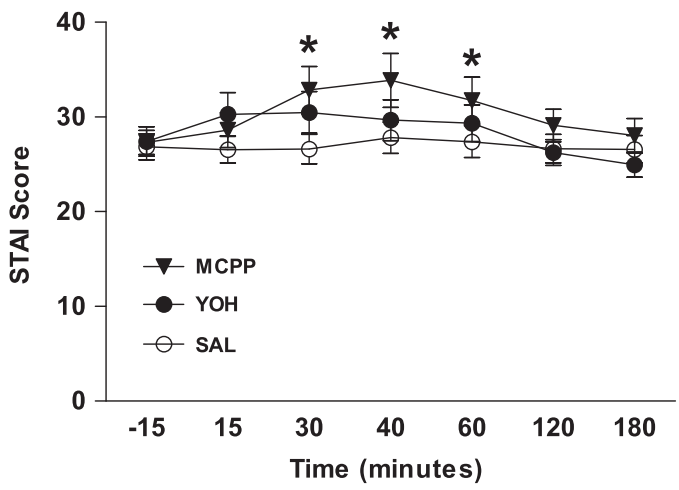

Figure 4 Effects of yohimbine and $\mathrm{mCPP}$ challenge on anxiety. Main challenge effect: $p<0.000$ I; $p<<0.05$ compared with saline on NewmanKeuls post hoc tests at individual time-points. Data are means \pm SEM. For detailed statistics, see Results.

and 60 min time points compared with the saline condition (Newman-Keuls post hoc tests, all $p<0.05$; Figure 4) while no such effect was seen with yohimbine. There was no significant effect of acamprosate treatment on anxiety during the challenge treatments $(\mathrm{F}(1,18)=2.52, p=0.013)$.

\section{Biochemical Measures}

Prolactin. There was a main effect of challenge $(\mathrm{F}(2,28)=$ $11.85, p=0.0002)$, a main effect of time point $(\mathrm{F}(6,84)=$ $11.24, p<0.00001)$, and an interaction of challenge and time point $(\mathrm{F}(12,168)=17.8, p<0.00001)$ on prolactin levels. Nicotine dependence score $(\mathrm{F}(1,14)=9.24, p=0.009)$ and ASI Psychiatric Problems score $(\mathrm{F}(1,15)=4.51, p=0.05)$ were significant covariates in the final model. The yohimbine challenge resulted in the highest elevations of prolactin at the 30,40, and $60 \mathrm{~min}$ time points, all of which were significantly different from both $\mathrm{mCPP}$ and saline (Newman-Keuls post hoc tests, all $p<0.001$ ). The mCPP challenge resulted in significantly higher prolactin levels compared with the saline condition at the $30,40,60,120$, and 180 min time points (Newman-Keuls post hoc tests, all $p<0.05)$. Prolactin measures did not correlate with either of the subjective alcohol craving measures during the challenges.

\section{ACTH}

There was a main effect of challenge $(\mathrm{F}(2,34)=9.2$, $p=0.0007)$, a main effect of time point $(\mathrm{F}(6,102)=31.1$, $p<0.00001)$, and an interaction of challenge and time point $(\mathrm{F}(12,204)=6.51, p<0.00001)$ on ACTH levels. In the final model, CDT\% was a significant covariate $(\mathrm{F}(1,17)=4.41$, $p=0.05$ ), and ethnicity was included because it reduced the residual variance by more than $10 \%$. Both the $\mathrm{mCPP}$ and the yohimbine challenges resulted in significant elevations of ACTH at the 30, 40, and 60 min time points compared with the saline condition (Newman-Keul post-hoc tests, all $p<0.01$; Figure $5 \mathrm{~b}$ ). There was no significant effect of acamprosate treatment on ACTH levels. ACTH measures did not correlate with either of the subjective alcohol craving measures during the challenges.

\section{Cortisol}

There was a main effect of challenge $(\mathrm{F}(2,36)=13.0$, $p=0.00006)$, a main effect of treatment $(\mathrm{F}(1,18)=5.98$, $p=0.03)$, a main effect of time point $(\mathrm{F}(6,108)=9.1$, $p<0.00001$ ), a two-way interaction of time point and challenge $(\mathrm{F}(12,216)=9.8, p<0.00001)$, and a three-way interaction of treatment, challenge, and time point $(\mathrm{F}(12$, $216)=2.25, p=0.01$ ) on cortisol levels. The number of drinking days in the past 30 days was a significant covariate in the final model $(\mathrm{F}(1,18)=10.5, p=0.005)$, while ethnicity was included because it reduced the residual variance by more than $10 \%$. In placebo-treated subjects, mCPP and yohimbine challenge resulted in significant elevations of cortisol compared with saline at the 30,40,60, and 120 min time points (Newman-Keuls post hoc tests, all $p<0.05$; Figure $5 \mathrm{c}$ ). Results were similar in the acamprosate-treated subjects, with both $\mathrm{mCPP}$ and yohimbine challenge resulting in significant elevations of cortisol at the 30, 40, and 60 min time points (Newman-Keuls post hoc tests, all $p<0.05$; Figure 5d). However, acamprosate-treated subjects showed further elevation of cortisol levels under the yohimbine challenge, such that at the $120 \mathrm{~min}$ time point, their cortisol levels were significantly higher compared with both saline and mCPP (Newman-Keuls post hoc tests, both $p<0.05$; Figure $5 \mathrm{~d}$ ). Cortisol measures did not correlate with either of the subjective alcohol craving measures during the challenges.

\section{DISCUSSION}

This is to our knowledge the first report of using a pharmacological alcohol craving provocation and an established alcoholism medication to validate a surrogate marker strategy. Both challenges used induced significant craving responses, assessed with PACS, a rating scale with established predictive validity (Flannery et al, 2003). The craving response to $\mathrm{mCPP}$ in our study was similar in magnitude to that previously reported on some (but not all) craving-related items using visual analog scales (Krystal et al, 1994). In contrast, the same study did not find a craving response to yohimbine, and in fact registered a decrease in craving-related ratings compared with placebo. Yohimbine has recently been shown to induce relapse-like behavior, ie reinstatement of alcohol seeking following extinction in rats (Le et al, 2005). Demonstration of its abililty to induce alcohol craving in humans using a validated rating scale therefore has considerable translational value.

Although less craving was induced by our pharmacological challenge stimuli than has been reported using psychological methods (Fox et al, 2007), the validity of our paradigm is supported by the observation that yohimbine- and mCPP-induced craving was most pronounced in individuals with the greatest severity of alcohol dependence. The relationship between craving and alcohol dependence severity, as measured by the ADS, thus accounts for a proportion of variation in yohimbine- and mCPP-induced craving responses, and fulfills a key objective for establishing laboratory paradigms to study alcohol craving (Sinha, 2009). Although robust endocrine responses to the challenge stimuli were also obtained, these 

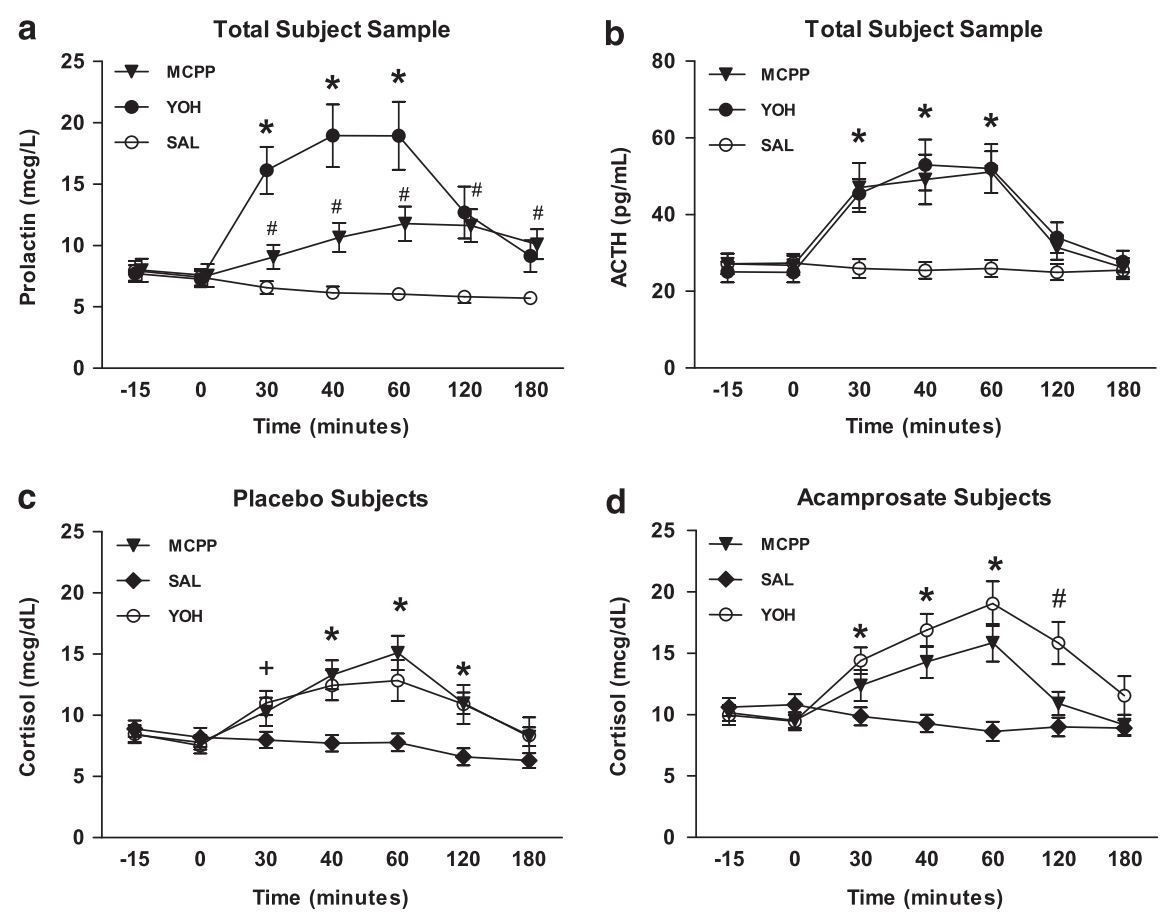

Figure 5 Effects of yohimbine and mCPP challenge on biochemical measures. (a) Prolactin levels were elevated by both yohimbine and $m C P P$ challenge compared with the saline condition, with a main challenge effect $p<0.000$ I. The yohimbine challenge resulted in the highest elevations of prolactin at the 30 , 40, and 60 min time points (* indicates a significant difference from both mCPP and saline, Newman-Keuls post hoc tests, all $p<0.00$ I). The mCPP challenge resulted in significantly higher prolactin levels compared with the saline condition at the 40,60, 120, and I80 min time points (\# indicates a significant difference from the saline condition, Newman-Keuls post hoc tests, all $p<0.05$ ). (b) ACTH levels were elevated by both yohimbine and mCPP challenge compared with the saline condition at the 30,40, and 60 min time points (* indicates a significant difference from the saline condition for both $\mathrm{mCPP}$ and yohimbine, Newman-Keuls post hoc tests, all $p<0.05$ ). (c) In placebo treated subjects, cortisol levels were elevated by both yohimbine and $\mathrm{mCPP}$ challenge compared with the saline condition at the 40,60, and 120 min time points (* indicates a significant difference from the saline condition for both mCPP and yohimbine, while ${ }^{+}$indicates a significant difference between saline and yohimbine only, Newman-Keuls post hoc tests, all $p<0.05$ ). (d) In acamprosate treated subjects, cortisol levels were elevated by both yohimbine and mCPP challenge compared with the saline condition at the 30, 40, and 60 min time points (* indicates a significant difference from the saline condition for both $m$ CPP and yohimbine, Newman-Keuls post hoc tests, all $p<0.05$ ). The combination of yohimbine and acamprosate resulted in further elevation of cortisol levels, such that at the 120 min time point cortisol levels were significantly higher compared with both mCPP and saline (\# indicates a significant difference from both mCPP and saline, Newman-Keuls post hoc tests, both $p<0.05$ ). All data are means \pm SEM.

did not correlate with subjective cravings. The mCPP also induced a significant anxiety response, providing additional support for the validity of our paradigm, since induction of anxiety (as measured by the STAI in other laboratory investigations) is correlated with the urge to drink in the field (Litt et al, 2000).

Although acamprosate is clinically effective for reducing relapse in alcoholism, it did not affect any of the craving outcomes in our model. It is possible that the reasons for this are primarily technical. First, $\mathrm{mCPP}$ and yohimbine induced only a moderate magnitude of craving, possibly resulting in insufficient sensitivity to detect a small effect size of acamprosate. Second, 2 weeks of acamprosate may have been insufficient to achieve maximal brain exposure (Hammarberg et al, 2010). The lack of an acamprosate effect on yohimbine-induced craving in particular, and the increased cortisol noted in the acamprosate group that received yohimbine, may also be related to previous observations that acamprosate can potentiate yohimbineinduced noradrenergic toxicity (Wilde and Wagstaff 1997). This points to a potential problem with screening new drugs for efficacy using pharmacologically induced craving, if a potential exists for drug interactions between the agent tested and the drug used to induce craving. Finally, however, it is possible that acamprosate in fact produces its clinical effects through actions unrelated to modulation of stress responses, as suggested by its inability to block stressinduced reinstatement of heroin-seeking in rats (Spanagel et al, 1998). This illustrates that surrogate markers may have to be tailored to the target mechanism for the specific therapeutic under evaluation.

It might be possible to augment craving induced by pharmacological stimuli by incorporating additional modalities of stimuli. For example, neither craving induced by negative mood, nor craving induced by alcohol-associated cues alone predicted relapse, but the combination of both these stimuli did predict relapse (Cooney et al, 1997; Sinha, 2009; Sullivan et al, 1989). Laboratory paradigms to study craving have included a number of modalities that could be combined: (1) exposure to alcohol-associated cues, eg alcohol odors, containers, and the presence of surrogate drinking partners in a bar-like setting; (2) alcohol ingestion, ie priming doses of alcohol; (3) a state of alcohol withdrawal achieved by studying alcoholics during early abstinence; (4) induction of negative mood, eg through the use of guided imagery; or (5) induction of craving through exposure to a 
social stressor, eg achieved through public speaking (Sinha and O'Malley, 1999; Litt and Cooney 1999; Sinha 2009; George et al, 2008). Given yohimbine's mechanism of action, combining it with other types of stimuli might act synergistically. Yohimbine is thought to potentiate transmitter release by noradrenergic Locus Coeruleus (LC) neurons through blockade of $\alpha_{2}$-autoreceptors, but this effect is activity dependent (Goldberg and Robertson, 1983). Potentiation occurs when LC activity is induced by environmental stimuli. However, when minimal environmental stimuli are present to drive LC activity, yohimbine may have little effect. Thus, the combination of yohimbine with some form of environmental stimulation, such as a psychological stressor or an alcohol cue, might augment yohimbine-induced craving.

In summary, both yohimbine and $\mathrm{mCPP}$ induced a moderate degree of craving for alcohol in treatment-seeking alcoholics during early abstinence. Two weeks of pretreatment with acamprosate did not modify these effects. It is presently unclear whether this is due to technical reasons, most importantly insufficient sensitivity, or because acamprosate has a mechanism of action that is independent of stress-related pathways activated by the stimuli used in our model. Pharmacologically induced alcohol craving remains an attractive surrogate marker approach to facilitating the development of alcoholism treatments, but may have to be augmented with psychological stimuli, and tailored to pharmacodynamic mechanisms through which candidate therapeutics are thought to exert their actions.

\section{ACKNOWLEDGEMENTS}

The authors thank MJ Phillips, BS for technical assistance, LE Kwako, PhD for providing comments on the article, and the NIH Clinical Center Pharmaceutical Development Services for formulating drug and placebo. This research was supported by NIAAA intramural research funding.

\section{DISCLOSURE}

The authors declare no conflict of interest.

\section{REFERENCES}

Anton RF, Moak DH, Latham PK (1996). The obsessive compulsive drinking scale: A new method of assessing outcome in alcoholism treatment studies. Arch Gen Psychiatry 53: 225-231.

Besson J, Aeby F, Kasas A, Lehert P, Potgieter A (1998). Combined efficacy of acamprosate and disulfiram in the treatment of alcoholism: A controlled study. Alcohol ClinExp Res 22: 573-579.

Bohn MJ, Krahn DD, Staehler BA (1995). Development and initial validation of a measure of drinking urges in abstinent alcoholics. Alcohol Clin Exp Res 19: 600-606.

Brownell KD, Marlatt GA, Lichtenstein E, Wilson GT (1986). Understanding and preventing relapse. Am Psychol 41: 765-782.

Charney DS, Woods SW, Goodman WK, Heninger GR (1987). Neurobiological mechanisms of panic anxiety: biochemical and behavioral correlates of yohimbine-induced panic attacks. Am J Psychiatry 144: 1030-1036.

Chick J, Howlett H, Morgan MY, Ritson B (2000). United Kingdom Multicentre Acamprosate Study (UKMAS): a 6-month prospective study of acamprosate versus placebo in preventing relapse after withdrawal from alcohol. Alcohol Alcohol 35: 176-187.
Cooney NL, Litt MD, Morse PA, Bauer LO, Gaupp L (1997). Alcohol cue reactivity, negative-mood reactivity, and relapse in treated alcoholic men. J Abnorm Psychol 106: 243-250.

Epstein DH, Preston KL, Stewart J, Shaham Y (2006). Toward a model of drug relapse: an assessment of the validity of the reinstatement procedure. Psychopharmacology (Berl) 189: 1-16.

First MB, Spitzer RL, Gibbon M, Williams JBW (1997). Structured Clinical Interview for DSM-IV Axis I Disorders (SCID-I), Clinician Version. American Psychiatric Press: Washington DC.

Flannery BA, Poole SA, Gallop RJ, Volpicelli JR (2003). Alcohol craving predicts drinking during treatment: an analysis of three assessment instruments. J Stud Alcohol 64: 120-126.

Flannery BA, Volpicelli JR, Pettinati HM (1999). Psychometric properties of the Penn Alcohol Craving Scale. Alcohol Clin Exp Res 23: 1289-1295.

Fox HC, Bergquist KL, Hong KI, Sinha R (2007). Stress-induced and alcohol cue-induced craving in recently abstinent alcoholdependent individuals. Alcohol: Clin Exp Res 31: 395-403.

Funk CK, O'Dell LE, Crawford EF, Koob GF (2006). Corticotropinreleasing factor within the central nucleus of the amygdala mediates enhanced ethanol self-administration in withdrawn, ethanol-dependent rats. J Neurosci 26: 11324-11332.

Gehlert DR, Cippitelli A, Le AD, Hipskind PA, Hamdouchi C et al. (2007). 3-(4-chloro-2morpholin-4-yl-thiazol-5-yl)-8-(1-ethypropyl)-2,6-dimethly-imidazo[1,2-b]pyridazine:a novel brain-penetrant, orally available corticotropin-releasing factor receptor 1 antagonist with efficacy in animal models of alcoholism. J Neurosci 27: 2718-2726.

George DT, Benkelfat C, Rawlings RR, Eckardt MJ, Phillips MJ, Nutt DJ et al (1997). Behavioral and neuroendocrine responses to $\mathrm{m}$-chlorophenylpiperazine in subtypes of alcoholics and in healthy comparison subjects. Am J Psychiatry 154: 81-87.

George DT, Gilman J, Hersh J, Thorsell A, Herion D, Geyer C et al (2008). Neurokinin 1 receptor antagonism as a possible therapy for alcoholism. Science 319: 1536-1539.

Goldberg MR, Robertson D (1983). Yohimbine: a pharmacological probe for study of the alpha 2-adrenoreceptor. Pharmacol Rev 35: $143-180$.

Hammarberg A, Beck O, Eksborg S, Jayaram-Lindstrom N, Lindefeldt A, Andersson M et al (2010). Acamprosate determinations in plasma and cerebrospinal fluid after multiple dosing measured by liquid chromatography-mass spectroscopy: a pharmacokinetic study in healthy volunteers. Ther Drug Monit 32: 489-496.

Hammarberg A, Jayaram-Lindstrom N, Beck O, Franck J, Reid MS (2009). The effects of acamprosate on alcohol-cue reactivity and alcohol priming in dependent patients: a randomized controlled trial. Psychopharmacology (Berl) 205: 53-62.

Heilig M, Egli M (2006). Pharmacological treatment of alcohol dependence: target symptoms and target mechanisms. Pharm Therap 111: 855-876.

Heilig M, Koob GF (2007). A key role for corticotropin-releasing factor in alcohol dependence. Trends Neurosci 30: 399-406.

Heinz A, Lober S, Georgi A, Wrase J, Hermann D, Rey ER et al (2003). Reward craving and withdrawal relief craving: assessment of different motivational pathways to alcohol intake. Alcohol Alcohol 38: 35-39.

Hillemacher T, Bayerlein K, Wilhelm J, Frieling H, Sperling W, Kornhuber $J$ et al (2006). Prolactin serum levels and alcohol craving - an analysis using Lesch's typology. Neuropsychobiology 53: $133-136$.

Kranzler HR, Mulgrew CL, Modesto-Lowe V, Burleson JA (1999). Validity of the obsessive compulsive drinking scale (OCDS): does craving predict drinking behavior? Alcohol Clin Exp Res 23: 108-114.

Krystal JH, Webb E, Cooney N, Kranzler HR, Charney DS (1994). Specificity of ethanollike effects elicited by serotonergic and noradrenergic mechanisms. Arch Gen Psychiatry 51: 898-911. 
Le AD, Harding S, Juzytsch W, Funk D, Shaham Y (2005). Role of alpha-2 adrenoceptors in stress-induced reinstatement of alcohol seeking and alcohol self-administration in rats. Psychopharmacology (Berl) 179: 366-373.

Le AD, Harding S, Juzytsch W, Watchus J, Shalev U, Shaham Y (2000). The role of corticotrophin-releasing factor in stressinduced relapse to alcohol-seeking behavior in rats. Psychopharmacology (Berl) 150: 317-324.

Litt MD, Cooney NL (1999). Inducing craving for alcohol in the laboratory. Alcohol Res Health 23: 174-178.

Litt MD, Cooney NL, Morse P (2000). Reactivity to alcohol-related stimuli in the laboratory and in the field: predictors of craving in treated alcoholics. Addiction 95: 889-900.

Littleton J, Zieglgansberger W (2003). Pharmacological mechanisms of naltrexone and acamprosate in the prevention of relapse in alcohol dependence. Am J Addict 12(Suppl 1): S3-S11.

Liu X, Weiss F (2002). Additive effort of stress and drug cues on reinstatement of ethanol seeking:exacerbation by history of dependence and role of concurrent activation of corticotropinreleasing factor and apioid mechanisms. J Neurosci 22: 7856-7861.

Marinelli PW, Funk D, Juzytsch W, Harding S, Rice KC, Shaham Y et al (2007). The CRF1 receptor antagonist antalarmin attenuates yohimbine-induced increases in operant alcohol self-administration and reinstatement of alcohol seeking in rats. Psychopharmacology (Berl) 195: 345-355.

McLellan AT, Kushner H, Metzger D, Peters R, Smith I, Grissom G et al (1992). The fifth edition of the addiction severity index. J Subst Abuse Treat 9: 199-213.

McLellan AT, Lewis DC, O'Brien CP, Kleber HD (2000). Drug dependence, a chronic medical illness: implications for treatment, insurance, and outcomes evaluation. JAMA 284: 1689-1695.

Monti PM, Rohsenow DJ, Rubonis AV, Niaura RS, Sirota AD, Colby SM et al (1993). Alcohol cue reactivity: effects of detoxification and extended exposure. J Stud Alcohol 54: 235-245.

Morley KC, Teesson M, Reid SC, Sannibale C, Thomson C, Phung $\mathrm{N}$ et al (2006). Naltrexone versus acamprosate in the treatment of alcohol dependence: a multi-centre, randomized, doubleblind, placebo-controlled trial. Addiction 101: 1451-1462.

O’Malley SS, Krishnan-Sarin S, Farren C, Sinha R, Kreek MJ (2002). Naltrexone decreases craving and alcohol self-administration in alcohol-dependent subjects and activates the hypothalamopituitary-adrenocortical axis. Psychopharmacology (Berl) 160: 19-29.

Ooteman W, Koeter MW, Verheul R, Schippers GM, van den Brink $\mathrm{W}$ (2007). The effect of naltrexone and acamprosate on cueinduced craving, autonomic nervous system and neuroendocrine reactions to alcohol-related cues in alcoholics. Eur Neuropsychopharmacol 17: 558-566.

Paille FM, Guelfi JD, Perkins AC, Royer RJ, Steru L, Parot P (1995). Double-blind randomized multicenter trial of acamprosate in maintaining abstinence from alcohol. Alcohol Alcohol 30: 239-247.
Pelc I, Verbanck P, Lebon O, Gavrilovic M, Lion K, Lehert P (1997). Efficacy and safety of acamprosate in the treatment of detoxified alcohol-dependent patients - A 90-day placebo-controlled dosefinding study. Br J Psychiatry 171: 73-77.

Sinha R (2009). Modeling stress and drug craving in the laboratory: implications for addiction treatment development. Addict Biol 14: 84-98.

Sinha R, Garcia M, Paliwal P, Kreek MJ, Rounsaville BJ (2006). Stress-induced cocaine craving and hypothalamic-pituitaryadrenal responses are predictive of cocaine relapse outcomes. Arch Gen Psychiatry 63: 324-331.

Sinha R, O'Malley SS (1999). Craving for alcohol: findings from the clinic and the laboratory. Alcohol Alcohol 34: 223-230.

Skinner H, Horn J (1984). Alcohol Dependence Scale: User's Guide. Addiction Research Foundation: Toronto.

Sobell LC, Sobell MB (1992). Timeline follow-back: a technique for assessing self-reported ethanol consumption. In: Allen J, Litten R (eds). Measuring Alcohol Consumption: Psychosocial and Biochemical Methods. Humana Press: Totowa, NJ. pp 41-72.

Southwick SM, Krystal JH, Bremner JD, Morgan III CA, Nicolaou AL, Nagy LM et al (1997). Noradrenergic and serotonergic function in posttraumatic stress disorder. Arch Gen Psychiatry 54: 749-758.

Spanagel R, Sillaber I, Zieglgansberger W, Corrigall WA, Stewart J, Shaham Y (1998). Acamprosate suppresses the expression of morphine-induced sensitization in rats but does not affect heroin self-administration or relapse induced by heroin or stress. Psychopharmacology (Berl) 139: 391-401.

Spielberger CD, Gorsuch RL, Lushene RE (1970). Manual for the State-Trait Anxiety Inventory. Consulting Psychologist Press: Palo Alto.

Stine SM, Southwick SM, Petrakis IL, Kosten TR, Charney DS, Krystal JH (2002). Yohimbine-induced withdrawal and anxiety symptoms in opioid-dependent patients. Biol Psychiatry 51: 642-651.

Sullivan JT, Sykora K, Schneiderman J, Naranjo CA, Sellers EM (1989). Assessment of alcohol withdrawal: the revised clinical institute withdrawal assessment for alcohol scale (CIWA-Ar). $\mathrm{Br}$ J Addict 84: 1353-1357.

Tempesta E, Janiri L, Bignamini A, Chabac S, Potgieter A (2000). Acamprosate and relapse prevention in the treatment of alcohol dependence: a placebo-controlled study. Alcohol Alcohol 35: 202-209.

Tiffany ST (1990). A cognitive model of drug urges and drug-use behavior: role of automatic and nonautomatic processes. Psychol Rev 97: 147-168.

Tiffany ST, Wray J (2009). The continuing conundrum of craving. Addiction 104: 1618-1619.

Wilde MI, Wagstaff AJ (1997). Acamprosate. A review of its pharmacology and clinical potential in the management of alcohol dependence after detoxification. Drugs 53: 1038-1053. 